\title{
O Combate ao Tráfico de Drogas na Fronteira Brasil-Bolívia (2008-2012) ${ }^{1}$
}

\author{
The Fight Against Drug Trafficking on \\ the Brazil-Bolivia Border (2008-2012)
}

DOI: $10.21530 /$ ci.v14n2.2019.873

Helena Salim de Castro ${ }^{2}$

\section{Resumo}

O tráfico internacional de drogas é uma das principais ameaças de segurança para os países da América do Sul, em especial o Brasil e a Bolívia. O país andino é o terceiro maior produtor mundial de cocaína e o território brasileiro é uma das principais rotas de trânsito para as drogas enviadas à Europa, bem como, é considerado o principal mercado consumidor para a cocaína boliviana. O objetivo central neste artigo é analisar a cooperação entre o Brasil e a Bolívia para o policiamento do combate ao tráfico de drogas. O recorte temporal abarcará o período entre novembro de 2008, quando a agência antidrogas estadunidense, Drug Enforcement Admnistration (DEA), foi expulsa do território boliviano, o que gerou uma aproximação entre os governos brasileiro e boliviano, até o final de janeiro de 2012, quando foi estabelecido um acordo trilateral entre Bolívia, Brasil e Estados Unidos. Analisar-se-á os acordos, reuniões e operações realizados pelas autoridades e burocracias brasileiras e bolivianas responsáveis pelas atividades de fiscalização e repressão ao tráfico de drogas, a fim de compreender como ocorreu a relação bilateral Brasil-Bolívia.

Palavras-chave: Cooperação; Tráfico de Drogas; Brasil; Bolívia.

1 O presente trabalho foi realizado com apoio da Coordenação de Aperfeiçoamento de Pessoal de Nível Superior

- Brasil (CAPES) - Código de Financiamento 001.

2 Mestre e Doutoranda em Relações Internacionais pelo Programa de Pós-Graduação San Tiago Dantas (UNESP, UNICAMP, PUC-SP). Professora Adjunta de Relações Internacionais na Universidade Paulista UNIP, Campus Swift, Campinas/SP. Membro do Grupo de Estudos sobre Conflitos Internacionais (GECI-PUC) e do Grupo de Estudos de Defesa e Segurança Internacional (GEDES-UNESP). Este artigo é resultado da minha dissertação de mestrado, a qual foi desenvolvida sob a orientação do Prof. Dr. Paulo José dos Reis Pereira.

Artigo submetido em 13/12/2018 e aprovado em 02/05/2019. 


\begin{abstract}
One of the main security threats to South American countries is international drug trafficking, especially in the case of Brazil and Bolivia. The Andean country is the third largest cocaine producer in the world and the Brazilian territory is one of the main drug trafficking to Europe, in addition, Brazil is the main consumer market for Bolivian cocaine. The central aim of this paper will be to analyze the cooperation between Brazil and Bolivia for the policing of the fight against drug trafficking. The time cut will cover the period between November 2008, when the United States antidrugs agency, Drug Enforcement Administration (DEA), was expelled from Bolivia, until the end of January 2012, when a trilateral agreement was signed among Bolivia, Brazil and United States. We will analyze the agreements, meetings and operations carried out by the Brazilian and Bolivian authorities and bureaucracies, which were responsible for the activities of control and repression of drug trafficking, in order to understend how the Brazil-Bolivia bilateral cooperation was.
\end{abstract}

Keywords: Cooperation; Drug Trafficking; Brazil; Bolivia.

\title{
Introdução
}

Neste artigo serão analisados as operações e os acordos estabelecidos pelas forças de segurança brasileiras e bolivianas entre os anos de 2008 e 2012, no que concerne ao combate ao tráfico de drogas na região de fronteira. Partimos das premissas de que o tráfico de drogas é um problema comum entre o Brasil e a Bolívia e que, com a expulsão da agência antidrogas dos Estados Unidos, Drug Enforcement Administration (DEA ${ }^{3}$ ), em novembro de 2008, do território boliviano, as instituições policiais e militares brasileiras configuraram-se como importantes parceiros operacionais da Bolívia no combate ao tráfico.

Nossa análise terá como marco final o acordo trilateral Bolívia, Brasil e Estados Unidos, assinado em janeiro de 2012. Esse acordo representou o retorno da parceria formal na luta antidrogas entre o país andino e a grande potência regional, após

3 A DEA foi criada em 1974, durante o governo do presidente Richard Nixon, com o objetivo de controlar e repreender o consumo e comércio de drogas nos Estados Unidos e no exterior, por meio de escritórios instalados ao redor do mundo. 
três anos da expulsão da DEA, cujo objetivo é aumentar a fiscalização e destruição das plantações de folha de coca excedentária ${ }^{4}$ no território boliviano.

O caráter transnacional do tráfico de drogas impulsiona os governos a elaborarem mecanismos de cooperação que permitam um eficaz combate à essa atividade ilícita. Essa situação é percebida na América do Sul. A complexidade e a dinâmica do tráfico de drogas afetam os países, conformando uma rede de produção, venda e consumo de substâncias ilícitas. Na região, encontram-se os maiores produtores de cocaína do mundo: Bolívia, Colômbia e Peru; os quais beneficiam-se da proximidade com o maior mercado consumidor da droga, os Estados Unidos. Ademais, os países sul-americanos destacam-se como países de trânsito de drogas, como é o caso da Venezuela e do Brasil.

O Brasil tem uma grande importância na dinâmica do tráfico de drogas na região sul-americana. É considerado um país de ciclo completo para o tráfico, no qual internamente ocorrem a produção, a venda e o consumo de drogas, além do uso do sistema financeiro local para a lavagem de dinheiro gerado por essa atividade ilícita (DREYFUS, 2009). A crescente importância do país na complexa rede de tráfico de drogas da América do Sul exige a elaboração de análises específicas sobre seu papel nesse contexto, principalmente considerando a necessidade de cooperação com os governos vizinhos diante da ameaça transfronteiriça.

A inserção internacional do Brasil no combate ao tráfico de drogas iniciou-se nos anos de 1990 (PROCÓPIO FILHO; VAZ, 1997). Em paralelo com uma política externa participativa nos regimes internacionais, houve uma preocupação maior do governo com o uso e o tráfico de drogas dentro do território. A extensa região de fronteira compartilhada com a Bolívia, devido ao grande fluxo de atividades ilegais, ganha destaque nessa questão. O país andino é atualmente o terceiro maior produtor de cocaína da América do Sul e o principal exportador da droga para o Brasil. Pretende-se, portanto, analisar neste artigo a cooperação em atividades de policiamento no combate ao tráfico de drogas entre o Brasil e a Bolívia, levando em conta o contexto social e político de ambos os países e o papel das instituições nacionais para o estreitamento da cooperação bilateral.

4 O cultivo de folha de coca excedentária é aquele que ocorre em áreas não autorizadas pelo governo, as quais devem ser erradicadas, e também se refere à folha de coca produzida em áreas autorizadas, mas que excede a quantidade permitida pelas autoridades, ficando sujeita a racionalização e sanções administrativas. Em 2017, foi aprovada a nova Lei Geral sobre Coca na Bolívia, que substituiu a de 1988, e traz novas permissões e regras para o cultivo e comercialização da folha de coca no país (BOLIVIA, 2017). Atualmente, é permitido o cultivo de folha de coca em um espaço de até 22.000 hectares na Bolívia (NACIONES UNIDAS, 2018). 
Ao discorrer sobre os elementos que caracterizaram essa cooperação, o presente artigo visa contribuir com uma área recente na literatura sobre crimes transfronteiriços, que se refere à discussão sobre a importância de analisar o policiamento conjunto entre agentes e instituições, como polícias e Forças Armadas, de diferentes países. Na literatura sobre a cooperação entre a Bolívia e o Brasil, há alguns autores que destacam a importância da diplomacia presidencial e o papel de atores estatais, como os ministérios das Relações Exteriores e da Justiça (BIATO, 2012). Ainda nessa linha de análise, o tema do combate às drogas é recorrentemente apresentado como uma das áreas dentro de um escopo maior da cooperação entre os dois países, que teria aumentado a partir da ascensão de governos com alinhamentos ideológicos próximos (GISBERT, 2011; HIRST, 2013). De outro lado, encontram-se autores que observam os aspectos técnicos da cooperação, analisando o impacto da presença do narcotráfico na região e as estratégias de combate que deveriam ser aplicadas (SCHULTZ-KRAFT, 2010), principalmente visando uma melhoria da gestão pública nas cidades-gêmeas entre os dois países (DEL PRADO, 2012; DIAS JÚNIOR; CRIVELATTI; COSTA, 2013; GIMENEZ, 2015 ).

Dialogando com essa literatura, pretendemos destacar a importância e a autonomia das burocracias estatais no processo de cooperação internacional, mais especificamente o protagonismo que o Ministério da Justiça e a Polícia Federal brasileira tiveram nas ações de policiamento conjunto para o combate ao tráfico de drogas na fronteira com a Bolívia. Para isso, o artigo será dividido em três sessões, para além desta Introdução e das Considerações Finais. Na primeira sessão, abarcaremos uma discussão sobre as características e elementos que impulsionaram a aproximação entre Brasil e Bolívia no que concerne à temática do tráfico de drogas, principalmente a partir dos anos 2000. Posteriormente, na segunda sessão, serão apresentados e discutidos os principais acordos assinados entre as autoridades brasileiras e bolivianas ao longo dos anos de 2008 e 2012 . Assim, em seguida, na última sessão, é possível apresentar e discutir as operações e os exercícios conjuntos realizados na região de fronteira entre os dois países, os quais deram o tom da cooperação bilateral Brasil-Bolívia.

\section{Um breve histórico da aproximação Brasil-Bolívia na questão do tráfico de drogas}

O Brasil e a Bolívia são países importantes na rede transnacional de tráfico de drogas. O país andino é o terceiro maior produtor mundial de cocaína. De acordo 
com o relatório da Junta Internacional de Fiscalização de Entorpecentes (JIFE) (NACIONES UNIDAS, 2018), de 2015 para $2016^{5}$ houve um aumento de $14 \%$ na área de cultivo da folha de coca (matéria-prima para a produção da cocaína) no território boliviano (de 20.200ha para 23.100ha). O Brasil, por sua vez, é considerado um dos maiores mercados consumidores de cocaína do Cone Sul. De 2004 a 2010, triplicou o número de apreensões federais de cocaína no Brasil, chegando a 27 toneladas (UNITED NATIONS, 2012). Além do consumo interno, o território brasileiro consolidou-se como uma das principais rotas de trânsito para a droga produzida nos Andes. Entre 2012 e 2016, o Brasil foi o segundo país mais mencionado como local de partida da cocaína apreendida que teria como destino os mercados europeus e o principal local de partida ou trânsito para a cocaína traficada para a Ásia (UNITED NATIONS, 2018).

A proximidade entre os dois países facilita o fluxo do tráfico. A maior fronteira terrestre brasileira é compartilhada com a Bolívia, assim como a do território boliviano é aquela compartilhada com o Brasil. Três dos maiores departamentos bolivianos fazem divisa com estados brasileiros: Pando (Bolívia) faz divisa com o Acre e Rondônia (Brasil); Beni (Bolívia) faz divisa com Rondônia; e Santa Cruz (Bolívia) faz divisa com Rondônia, Mato Grosso e Mato Grosso do Sul (Brasil). Uma das principais saídas para a cocaína boliviana é o departamento de Santa Cruz e o departamento de Beni. Nesse último, há uma grande concentração de pistas de pouso clandestinas para aeronaves utilizadas pelos traficantes bolivianos e estrangeiros para enviar a cocaína processada em Cochabamba até o estado de Rondônia, no Brasil (SCHULTZE-KRAFT, 2010).

A preocupação com o tráfico de drogas na região de fronteira é uma questão que perpassa a história das relações bilaterais dos países. A formalização da cooperação entre Brasil e Bolívia para o combate aos ilícitos fronteiriços data da assinatura do Convênio de Assistência Recíproca para Repressão ao Tráfico de Ilícitos de Drogas que Produzem Dependência, de 1977, o qual ainda se encontra vigente. Esse acordo estabeleceu a necessidade dos países de cooperar na troca de informações e intercâmbio de pessoal para treinamentos, e designou os organismos policiais como os responsáveis pela repressão ao tráfico de drogas, em seus respectivos territórios (BRASIL, 1977). Em 1988, foi assinado um protocolo adicional ao Convênio de 1977 (BRASIL, 1988), porém ainda está "em tramitação", de acordo com o Sistema de Atos Internacionais do Ministério das Relações Exteriores.

5 O relatório ressalta que, embora tenha havido esse aumento, a área utilizada para cultivo de coca ainda é menor que o observado em anos anteriores, como 2006 (27.500 ha) e 2010 (31.000 ha) (NACIONES UNIDAS, 2018). 
A cooperação nessa temática não ocupou, entretanto, um espaço de destaque na agenda bilateral durante o século XX. O Brasil manteve-se distante dos principais debates e discussões regionais sobre o tráfico de entorpecentes. Ademais, ao longo dos anos de 1980, o principal parceiro da Bolívia nas ações de combate ao tráfico de drogas era os Estados Unidos (LEICHTMAN, 2000). O governo estadunidense, sob a justificativa da "guerra às drogas”, liderou e financiou diversas operações no território boliviano, como as operações Blast Furnace ${ }^{6}$, em 1986, e Snow Cap ${ }^{7}$, em 1987, o que colocava o país como o principal ator estrangeiro na luta antidrogas na Bolívia (RODRIGUES, 2012).

Apenas em 1999 outro acordo de destaque foi assinado entre Bolívia e Brasil, o qual entrou em vigor em março de 2004: o Acordo de Cooperação para Impedir o Uso Ilegal de Precursores e Substâncias Químicas Essenciais para o Processamento de Entorpecentes e Substâncias Psicotrópicas (BRASIL, 1999). Esse acordo foi estabelecido em um contexto no qual o governo dos Estados Unidos voltou seus esforços antidrogas para a Colômbia (Plano Colômbia), que alcançava o posto de principal produtor mundial de cocaína. Não obstante, o governo estadunidense ainda permanecia como importante parceiro da Bolívia.

Com o início do século XXI, um novo contexto social e político interferiu no relacionamento entre Bolívia e Estados Unidos. O início do novo milênio é marcado pelo acirramento das manifestações populares no país andino, principalmente por parte de camponeses e cocaleros ${ }^{8}$ insatisfeitos com a repressão ao cultivo da folha de coca e com a influência estadunidense na política antidrogas boliviana. A instabilidade interna, juntamente com o fracasso das operações antidrogas, contribuiu para a ascensão do candidato do Movimento para o Socialismo (MAS), o líder indígena e cocalero Evo Morales, à presidência da Bolívia. Eleito em 2005, Morales transformaria a histórica relação de seu país com a grande potência.

Com claras divergências ideológicas, refletidas na aproximação do presidente boliviano de antigos rivais estadunidenses (Venezuela, Cuba e Irã) e na manutenção

6 A Operação Blast Furnace ocorreu em julho de 1986. Na ocasião, militares estadunidenses e agentes da DEA lideraram as tropas bolivianas em ações para destruir laboratórios de refinamento de cocaína localizados na selva boliviana (RODRIGUES, 2012).

7 Um ano após a Operação Blast Furnace, o governo boliviano, novamente com o auxílio estadunidense, lançou uma nova operação que tinha como objetivo diminuir a quantidade de cocaína enviada aos Estados Unidos, em um prazo de três anos (RODRIGUES, 2004).

8 Trata-se de um movimento social formado por indígenas e antigos mineradores - os quais, após a crise econômica do setor, foram demitidos - que têm no cultivo da folha de coca o seu sustento. Considerados os representantes da "vanguarda esquerdista" da Bolívia, os cocaleros constituem a base do Movimento para o Socialismo (MAS) (SOUSA, 2010). 
de uma retórica anti-imperialista e antiamericanista na política externa (BRIENEN, 2015), a relação entre Bolívia e Estados Unidos ganharia novos contornos principalmente no que se refere à política antidrogas. Contrariando a norma internacional de condenação ao cultivo de qualquer substância entorpecente, Morales manteve e expandiu a política do "cato", a qual foi criada pelo seu antecessor e garantia o direito de cada família boliviana cultivar folha de coca num espaço de $1.600 \mathrm{~m}^{2}$ (medida do cato), e investiu em uma política internacional de revalorização da planta (GRISAFFI; LEDEBUR, 2016).

Não obstante, o rompimento da relação entre os países teve como marco inicial o envolvimento da embaixada estadunidense nas divergências políticas internas da Bolívia. Os partidos de oposição à administração de Morales reivindicavam a autonomia departamental em relação ao governo central, principalmente no que concernia à arrecadação de impostos referentes à exploração e comercialização de hidrocarbonetos (LISBOA, 2015). Nesse contexto de tensão política interna, foi realizada uma reunião secreta, em agosto de 2008, entre o embaixador dos Estados Unidos na Bolívia, Phillipe Goldeberg, e o governador da oposição, do departamento de Santa Cruz, a qual foi interpretada por Morales como uma tentativa do governo estadunidense de comandar um processo separatista no país andino (LISBOA, 2015,). Esse fato gerou a expulsão do embaixador em setembro do mesmo ano e o rompimento das relações diplomáticas entre os dois países.

Em retaliação à ação boliviana, os Estados Unidos também expulsaram o embaixador da Bolívia em Washington e promoveram a "desertificação" do país, incluindo-o na lista daqueles não cumpridores das metas de combate às drogas (MAYORGA, 2009). Apesar dos esforços bolivianos e dos resultados positivos quanto à diminuição do cultivo de coca, o presidente George W. Bush vetou a proposta de ampliação do ATPDEA (Decreto de Promoção Comercial Andina e Erradicação de Drogas) - assinado em 2002 - para mais seis meses, a partir de outubro de 2008. Mesmo sob a administração de Obama, o veto permaneceu, ocasionando no expiro definitivo do acordo em julho de 2009 (DELGADO; CUNHA FILHO, 2010).

Essa sequência de desentendimentos entre os dois países culminou na suspensão das atividades da Agência dos Estados Unidos para o Desenvolvimento Internacional (USAID) e na expulsão da DEA. Sob suspeita de envolvimento com atividades de espionagem e devido às diversas acusações de desrespeito aos direitos humanos e de uso de violência contra a população, a agência antidrogas foi expulsa da Bolívia em novembro de 2008 (MAYORGA, 2009; BRIENEN, 2015). No entanto, cabe assinalar que o governo estadunidense continuou a contribuir 
financeiramente para a redução do tráfico de cocaína na Bolívia. Como analisado por Lisboa (2015), a Seção de Assuntos de Narcóticos (NAS, na sigla em inglês), dos Estados Unidos, enviou recursos financeiros para a realização de operações da Força Especial de Luta Contra o Narcotráfico (FELCN) e outras unidades policiais bolivianas, pelo menos até o ano de 2012. A expulsão da DEA significou, portanto, uma ruptura na cooperação militar e policial entre os dois países.

Sem o apoio operacional dos Estados Unidos, o governo boliviano reformularia suas parcerias internacionais, pois mesmo com a política de revalorização da folha de coca, manteve-se uma postura combativa com relação ao tráfico de cocaína. A partir de 2008, por exemplo, as Forças Armadas do país passaram a atuar diretamente no combate ao tráfico (MAYORGA, 2009). Assim, para garantir uma postura repressiva com relação aos grupos traficantes de cocaína, a Bolívia buscou outros parceiros na luta contra o tráfico, sendo um deles o Brasil, representado, principalmente, pelo Departamento da Polícia Federal (DPF).

\section{Os acordos estabelecidos entre Brasil e Bolívia de 2008 a 2012}

Conforme mencionado, já havia um histórico de acordos estabelecidos entre o Brasil e a Bolívia sobre a temática do tráfico de drogas. No entanto, essa cooperação ganhou maior expressão a partir de 2008. A expulsão da DEA do país andino, a necessidade de manter um controle do tráfico na região e o contexto social e político da época foram alguns dos elementos que contribuíram para o reforço da cooperação. Nos primeiros anos do século XXI, os dois países aproximaram-se, em grande parte em decorrência da diplomacia presidencial exercida por Luís Inácio Lula da Silva, que foi capaz de aumentar o diálogo com os países da região (CASON; POWER, 2009). Na interpretação de Hirst (2013), a diplomacia presidencial, que caracterizou a administração de Lula, e um pretenso alinhamento ideológico entre o Partido dos Trabalhadores (PT) e o MAS facilitaram o estabelecimento de uma relação favorável entre os dois países.

Ademais, a expansão do tráfico de drogas no início do século XXI, juntamente com a expulsão da DEA do país andino, aproximariam as instituições brasileiras e bolivianas para atuarem em conjunto nessa questão No início dos anos 2000, a preocupação com a segurança pública e o tráfico de drogas configurou-se como a terceira área de maior relevância na parceria bilateral Brasil-Bolívia - precedida pelo setor energético e de infraestrutura (HIRST, 2013). Em uma entrevista em 2015, 
o ex-chanceler Celso Amorim9, afirmou que houve uma demanda por parte da Bolívia para a cooperação brasileira em substituição à cooperação estadunidense, a qual foi atendida pelo país (GIMENEZ, 2015). Um mês após a expulsão DEA, o presidente boliviano procurou o Ministério das Relações Exteriores (MRE) do Brasil para discutir o estabelecimento de uma cooperação para o combate ao tráfico de drogas.

Para o ex-embaixador boliviano em Brasília, Jerjes Justiniano Talavera, em serviço em 2015, os desentendimentos de seu país com os Estados Unidos, que culminaram na suspensão do ATPDEA e na expulsão da DEA, fizeram com que outros três países se comprometessem a ocupar o espaço deixado pela grande potência: Argentina, Venezuela e Brasil. Ademais, segundo Talavera, houve uma cooperação maior entre as polícias e exércitos brasileiros e bolivianos, tanto para execução de operações quanto no que concerne à oferta de treinamentos e cursos militares (GIMENEZ, 2015). Oslain Campos Santana, então diretor da Divisão de Investigação e Combate ao Crime Organizado Transnacional da Polícia Federal, relatou, em entrevista realizada em 2015, que a cooperação policial entre os dois países inseriu-se dentro de um acordo "guarda-chuva” de repressão ao narcotráfico já existente entre os governos, via o Ministério das Relações Exteriores (GIMENEZ, 2015).

No entanto, conforme assinalado por Amorim e observado em telegramas enviados da embaixada estadunidense em Brasília, o envolvimento do MRE na cooperação para o combate ao narcotráfico, entre os anos de 2008 e 2012, foi irrisória, em comparação com outros setores e ministérios brasileiros. Amorim afirmou que havia pouco conhecimento sobre esse tipo de cooperação na pasta do MRE e que foi apenas quando exerceu o cargo de ministro da Defesa, no governo de Dilma Rousseff (2011-2016), que participou de acordos com a Bolívia, os quais envolveram a doação de equipamentos brasileiros aos militares bolivianos (GIMENEZ, 2015).

Documentos revelados pelo portal do Wikileaks demonstram que a aproximação entre a Bolívia e o Brasil na questão do combate ao tráfico de drogas ocorreu mais em razão de pressões dos Estados Unidos e de interesses de órgãos burocráticos brasileiros, como o Ministério da Justiça e a Polícia Federal, do que por ímpeto

9 As entrevistas citadas ao longo do artigo foram realizadas pela pesquisadora Heloisa Marques Gimenez, ao longo do ano de 2015, e estão disponíveis em: GIMENEZ, Heloísa M. Defesa Nacional, Segurança Pública e Relações Internacionais: uma análise sobre a fronteira Bolívia-Brasil (2005-2014). 2015. 493 f. Tese (Doutorado em Relações Internacionais) Instituto de Relações Internacionais, Universidade de Brasília, Brasília, 2015. 
de política externa. Apesar de demonstrar interesse na cooperação com o governo boliviano, em razão da preocupação com o fluxo de cocaína entre os dois países, o Ministério das Relações Exteriores do Brasil, na época, assinalou um certo receio com a capacidade de substituir a DEA na Bolívia (WIKILEAKS2008).

Tal posicionamento também foi seguido inicialmente pela Polícia Federal brasileira (PF), que se indagou sobre a possibilidade de ocupar o espaço da agência estadunidense. No entanto, de forma oposta ao órgão de política exterior do país, a PF, agência vinculada ao Ministério da Justiça, assinalou um interesse da unidade em aumentar a presença de agentes da DEA no Brasil, a fim de auxiliar no combate regional ao tráfico de drogas (WIKILEAKS, 2008). Esse interesse da agência policial brasileira tinha sustentação em uma estratégia já assinalada pelo governo dos Estados Unidos.

Com a saída da DEA da Bolívia, o governo estadunidense optou por realocar os agentes expulsos em outros países sul-americanos, entre eles o Brasil. Para evitar transtornos com o Ministérios das Relações Exteriores do Brasil, que se opunha à criação de novos escritórios da agência no país, a solução encontrada pelas autoridades estadunidenses foi “inchar” os escritórios já existentes em São Paulo e Brasília. O governo dos Estados Unidos conseguiria manter, assim, esses agentes em atuação na região e aumentaria o engajamento do Brasil na cooperação regional. Solução apoiada e incentivada pelo Ministério da Justiça, Polícia Federal e governo brasileiros (WIKILEAKS, 2009a; CONROY; FRIEDMAN-RUDOVSKY; VIANA, 2011).

A influência estadunidense na política antidrogas do Brasil e, consequentemente, no tipo de cooperação que o país estabeleceria com seus vizinhos se daria de forma indireta, através da realização de treinamentos de agentes da Polícia Federal nos Estados Unidos e da doação de equipamentos para os escritórios brasileiros. No ano de 2009, foram doados computadores, impressoras, aparelhos de GPS, cães treinados para encontrar drogas e muitos outros equipamentos para os escritórios da PF de Brasília, das polícias civis e militares e unidades de investigação de outros estados brasileiros (WIKILEAKS, 2010). O Brasil, munido de expertise e instrumentos de ação garantidos pela DEA, passaria, a partir de então, a ser um importante parceiro da Bolívia na luta contra o tráfico de drogas.

Diante dessas movimentações, observamos que a cooperação para o combate ao tráfico de drogas entre o Brasil e a Bolívia ressalta a importância do Ministério da Justiça como o principal órgão estatal na elaboração de acordos com o vizinho andino. Já em 21 de novembro de 2008, os ministros da Justiça de ambos os países, Tarso Genro no Brasil e Celina Torrico na Bolívia, assinaram uma nota conjunta 
em que a Polícia Federal brasileira (PF) se comprometia a assumir o controle do combate ao tráfico de drogas no território boliviano. Era o início da reaproximação entre os dois países nessa temática. De acordo com a nota, a cooperação iria alcançar um novo patamar. Para além das trocas de informação e inteligência, o acordo propunha maior efetivo policial na fronteira e a atuação da PF em ações de destruição de pistas clandestinas e áreas ilegais de plantação de folha de coca localizadas na Bolívia (PF..., 2008).

A nota conjunta foi formalizada em 18 de fevereiro de 2009, quando a PF e a Polícia Nacional da Bolívia (PNB) assinaram um acordo de cooperação no combate ao crime organizado. $\mathrm{O}$ acordo foi assinado durante uma reunião que tratava da Estratégia de Cooperação Policial Brasil-Bolívia 2009, realizada na cidade de Campo Grande, Mato Grosso do Sul. O documento previa uma série de ações, com validade de um ano, como a troca de informações de inteligência, de treinamentos e apoio logístico em operações. O objetivo principal era combater a lavagem de dinheiro e o tráfico de drogas e armas (POLÍCIAS..., 2009). O Departamento da Polícia Federal havia emitido uma nota ${ }^{10}$ à embaixada brasileira em La Paz, no início do mês, para que se convidasse dois representantes da Força Aérea boliviana, atuantes nas operações de erradicação de cultivo de ilícitos, para participarem, como observadores, dessa reunião, que ocorreu entre os dias 17 e 19 de fevereiro.

Os adidos da Polícia Federal e dos militares, estabelecidos na embaixada brasileira em La Paz, também eram responsáveis por coordenar e convidar os agentes bolivianos para participar de seminários e treinamentos voltados para o combate ao crime organizado no Brasil. Roberto Severo Ramos, então chefe de gabinete do Estado-Maior Conjunto das Forças Armadas (EMCFA), em entrevista realizada em 2015, assinalou que as operações ostensivas que são executadas nas regiões de fronteira, como a Operação Ágata11, que se encontra sob o âmbito do Plano Estratégico de Fronteiras ${ }^{12}$ (Pefron), exige um grande esforço de planejamento

10 As informações sobre notas transmitidas e encontros de comissões entre autoridades do Brasil e da Bolívia foram retiradas dos telegramas compartilhados entre o MRE e a embaixada brasileira em La Paz, durante os anos de 2008 a 2012, disponíveis no arquivo histórico do Itamaraty.

11 A Operação Ágata, um dos eixos do Plano Estratégico de Fronteiras, é conduzida pelo Ministério da Defesa e consiste no emprego das Forças Armadas em pontos específicos da fronteira brasileira a fim de realizar operações de caráter pontual e temporário (ASSOCIAÇÃO NACIONAL DOS DELEGADOS DE POLÍCIA FEDERAL, 2011).

12 Em 8 junho de 2011, sob a administração da presidente Dilma Rousseff, foi lançado o Decreto $\mathrm{n}^{\circ}$ 7.496, que instituiu o Plano Estratégico de Fronteiras (Pefron). Sob a responsabilidade do vice-presidente da República, o Pefron tem o objetivo de reforçar a presença do Estado nas fronteiras terrestres do Brasil, através de ações de "fortalecimento da prevenção, controle, fiscalização e repressão dos delitos fronteiriços e dos delitos praticados na faixa de fronteira brasileira” (BRASIL, 2011). 
e transparência. De acordo com Ramos, sempre houve o convite para que o país vizinho participasse como observador dessas operações, o qual era realizado através dos adidos militares brasileiros estabelecidos na embaixada em La Paz (GIMENEZ, 2015).

Houve, entre os anos de 2008 e 2012, uma intensa relação via adidos militares, o que dinamizava as ações conjuntas de controle do crime organizado. Não havia uma participação direta dos governos federais. Era emitido o convite e cabia às autoridades bolivianas enviar representantes das Forças Armadas para observar as ações. Em 18 de outubro de 2010, foi emitida uma nota da embaixada brasileira em La Paz informando que os adidos da Polícia Federal confirmavam a participação de autoridades bolivianas no Seminário Internacional sobre Repressão ao Crime Organizado, para tratarem do tema da cooperação bilateral em matéria criminal Brasil-Bolívia, organizado pelo DPF e o Escritório das Nações Unidas sobre Drogas e Crimes (UNODC) em Brasília, entre os dias 27 e 29 de outubro do mesmo ano. Entre as autoridades bolivianas presentes no Seminário, estavam o chefe do UNODC na Bolívia e seis policiais da Força Especial de Luta contra o Narcotráfico (FELCN).

A realização do Seminário, além de refletir o interesse das autoridades brasileiras e bolivianas em fortalecer a cooperação bilateral, no que concerne ao combate do crime organizado, sinalizou a importância e a autonomia que determinadas burocracias estatais, no caso a Polícia Federal, tiveram na impulsão da cooperação para o policiamento. Durante a ocasião, o então diretor de luta contra a Delinquência Organizada da Polícia Federal, Roberto Trocon, assinalou que a Bolívia era um sócio estratégico do Brasil na luta contra a delinquência organizada na América do Sul. Ademais, o diretor defendeu a responsabilidade compartilhada no combate ao crime organizado na região (UNODC, 2010).

Ainda em 2010, no dia 16 de dezembro, na cidade de Foz do Iguaçu-PR, o ministro da Justiça brasileiro, Luiz Paulo Barreto, assinou um acordo com o ministro de Governo boliviano, Sacha Llorenty, a fim de ampliar a cooperação policial entre os dois países. O documento assinado estabeleceu cinco áreas em que a cooperação deveria ser expandida: i) formação e capacitação policial; ii) operações conjuntas e de inteligência; iii) lavagem de dinheiro; iv) fortalecimento das relações de fronteira; e v) questão migratória (CRUZ, 2010).

Ao longo de 2011, outras reuniões e acordos também foram celebrados entre as autoridades brasileiras e bolivianas. A preocupação em fiscalizar e proteger as fronteiras, representada pela criação de diversas políticas, em especial o Pefron, 
impulsionou o governo brasileiro a retomar a realização dos Comitês de Fronteira Boliviano-Brasileiros, idealizados desde 1997. Através de um acordo de troca de notas, assinado em 25 de março de 2011 pelos ministros das Relações Exteriores de ambos os países, foi proposta a criação de Comitês de Integração Fronteiriça nas cidades-gêmeas que ligam o Brasil e a Bolívia. O objetivo era promover uma integração das populações que habitam esses municípios e realizar ações no âmbito da segurança pública, saúde, esporte, entre outros (BRASIL, 2011).

Nesse mesmo ano, foi realizada a VII Comissão Mista sobre Drogas e Temas Conexos, no dia 30 de março, na cidade de La Paz. Durante a reunião foram celebradas algumas iniciativas conjuntas e renovados outros acordos. O ministro da Justiça do Brasil, José Eduardo Cardozo, na ocasião, anunciou que o escritório da UNODC na Bolívia receberia US\$100.000 (cem mil dólares) para implementação de políticas públicas voltadas ao combate ao crime organizado. Ambos os países também renovaram o acordo de cooperação bilateral até o ano de 2013 (UNODC, 2011), reforçando o interesse em dar continuidade às operações conjuntas na região de fronteira.

Apesar de o Ministério da Justiça ser o órgão principal na elaboração dos acordos referentes às questões de segurança pública, a participação dos militares na cooperação para o policiamento do tráfico de drogas, formalizada a partir das Leis $\mathrm{n}^{0} 117 / 04^{13}$ e $\mathrm{n}^{0} 136 / 10^{14}$, exigia a atuação de outras instituições e ministérios nos acordos celebrados com a Bolívia. Assim, no dia 31 de outubro de 2011, o então ministro da Defesa brasileiro, Celso Amorim, realizou uma visita à Bolívia com o objetivo de retomar a cooperação militar, em matéria de combate ao crime organizado, entre os dois países. O ministro expressou o interesse do Brasil em fortalecer a vigilância das fronteiras, através de um intercâmbio maior de inteligência militar e do uso compartilhado de radares e veículos aéreos não tripulados (VANTs) (MARREIRO, 2011).

Essa série de acordos, reuniões e notas conjuntas entre o Brasil e a Bolívia, realizados ao longo dos anos de 2008 a 2012, podem ser visualizados de forma resumida no quadro a seguir:

13 Lei Complementar $n^{\circ} 117$, sancionada em setembro de 2004, alterou a Lei Complementar $n^{\circ} 97$ de 1999 , a fim de estabelecer novas atribuições às Forças Armadas. Com essa lei, o Exército brasileiro obteve a prerrogativa de atuar em operações com outros órgãos federais para a repressão de delitos de repercussão nacional e internacional. A Marinha, a Aeronáutica e o Exército passariam a auxiliar, quando necessário, no apoio logístico, de inteligência, de comunicações e de instrução (BRASIL, 2004).

14 A prerrogativa de atuar com poder de polícia no combate ao tráfico de drogas, concedida ao Exército anteriormente na Lei $n^{\circ} 117$, foi ampliada para as demais Forças Armadas, Aeronáutica e Marinha, a partir da Lei Complementar $\mathrm{n}^{\circ} 136$, de 25 de agosto de 2010 . 


\section{Quadro 1 - Acordos e Reuniões celebrados entre as autoridades} brasileiras e bolivianas, 2008-2012

\begin{tabular}{|c|l|}
\hline DATA & \multicolumn{1}{c|}{ DENOMINAÇÃo } \\
\hline $21 / 11 / 2008$ & Nota Conjunta entre os ministros da Justiça do Brasil e da Bolívia. \\
$29-30 / 01 / 2009$ & VI Comissão Mista sobre Drogas e Temas Conexos. \\
$18 / 02 / 2009$ & Acordo de cooperação no combate ao crime organizado. \\
$27-28 / 10 / 2010$ & $\begin{array}{l}\text { Seminário Internacional sobre Repressão ao Crime Organizado para tratar do } \\
\text { tema da cooperação bilateral em matéria criminal Brasil-Bolívia. }\end{array}$ \\
$16 / 10 / 2010$ & Acordo de Cooperação Policial. \\
$25 / 03 / 2011$ & Acordo por Troca de Notas - Comitês de Integração Fronteiriça. \\
$30 / 03 / 2011$ & VII Comissão Mista sobre Drogas e Temas Conexos - renovação de acordos. \\
$31 / 10 / 2011$ & Visita do ministro da Defesa brasileiro à Bolívia - Cooperação Militar. \\
\hline
\end{tabular}

Fonte: elaborado pela autora com base nos arquivos oficiais do Itamaraty e reportagens de periódicos (2017).

De acordo com o ex-embaixador brasileiro em La Paz, Marcel Fortuna Biato (2012), a Bolívia constitui-se como principal sócio estratégico do Brasil na luta contra o crime transnacional. Ambos os países observavam o combate ao tráfico como uma responsabilidade a ser compartilhada, em que a confiança é o fator necessário para a aplicação de políticas eficazes, as quais se baseiam no "princípio do controle social da produção da folha de coca"15 (BIATO, 2012, p. 8). Por conseguinte, esses acordos, que contribuíram para a aproximação entre os dois países, impulsionaram algumas operações e ações conjuntas que foram realizadas na região de fronteira, a fim de combater os grupos traficantes de drogas.

\section{Uma análise sobre as operações na região de fronteira Brasil-Bolívia}

As mudanças legislativas que ocorreram no início dos anos 2000 no Brasil, Lei $\mathrm{N}^{0} 117 / 04$ e Lei $\mathrm{N}^{0} 136 / 10$, permitiram que os militares pudessem atuar diretamente na repressão aos grupos do crime organizado, exercendo um papel de polícia nas fronteiras. Essa prerrogativa aumentou o aparato repressivo do Estado. O contingente militar somou-se às ações já exercidas pelo Departamento da Polícia Federal e polícias estaduais. Ademais, a participação das Forças Armadas garantiu

15 De acordo com este princípio, é necessário o uso de políticas sociais e de desenvolvimento no tratamento com os cultivadores da folha de coca. 
que o Brasil pudesse ampliar seu escopo de cooperação com a Bolívia, país que já utilizava os militares nas tarefas de combate ao tráfico de drogas.

Machado $(2007,2010)$ discute as medidas institucionais de controle ao tráfico de drogas na região da Bacia Amazônica. De acordo com suas análises, a ampliação das atribuições das Forças Armadas para ações de repressão ao tráfico de ilícitos acaba por "confundir as atribuições constitucionais e a hierarquia institucional de cada órgão federal” (MACHADO, 2010, p. 100). De acordo com a Constituição Federal brasileira, a Polícia Federal é a instituição responsável pela repressão e fiscalização do tráfico de ilícitos (BRASIL, 2016), no entanto, as mudanças legislativas permitiram a participação cada vez maior de militares nessas operações.

Entre algumas das operações realizadas pelo Brasil nas cidades que fazem fronteira com a Bolívia, podemos citar a Operação Cadeado, a Cadeado VI e a Operação Curare III. A primeira Operação Cadeado foi desenvolvida pelo Exército em novembro de 2009, para fiscalizar as fronteiras do Brasil com a Bolívia e o Paraguai, através do estabelecimento de barreiras terrestres fixas nas estradas e o patrulhamento fluvial. Liderada pelo Comando Militar do Oeste (CMO), a operação contou com o apoio do DPF, do Ibama (Instituto Brasileiro do Meio Ambiente e dos Recursos Naturais Renováveis) e da Receita Federal. O objetivo da operação foi a repressão e a prevenção dos crimes transfronteiriços, dentre eles o tráfico de drogas (OPERAÇÃO..., 2009).

Em novembro de 2010, já com a Lei No 136/2010, o CMO, com o apoio das demais Forças Armadas, deflagrou outra operação com as mesmas características, a Operação Cadeado VI, também na região de fronteira com a Bolívia, em parceria com a Secretaria de Estado de Justiça e Segurança Pública (CUIABANO, 2010). A Curare III foi deflagrada pela $17^{\text {a }}$ Brigada de Infantaria de Selva, nos meses de setembro e outubro de 2011, nos estados do Acre e Rondônia, nas regiões de fronteira com a Bolívia e o Peru. O objetivo principal dessa operação foi fortalecer a presença do Exército na faixa de fronteira da Amazônia Ocidental brasileira, a fim de evitar a ocorrência de delitos transfronteiriços e ambientais (OPERAÇÃO CURARE III, 2011).

Essas operações tiveram em comum a realização de ações cívicas, em paralelo com aquelas de caráter ostensivo, como o estabelecimento de postos de atendimento à saúde da população. Não obstante, o investimento em políticas de desenvolvimento nesses municípios era e continua sendo irrisório, pois essas operações, na maioria das vezes, são de caráter temporário. De acordo com Alexandre Bastos Peixoto, que em 2015 realizava atividades como coordenador operacional da Comissão Permanente de Desenvolvimento e Integração da Faixa de 
Fronteira ${ }^{16}$ (CDIF), as demandas dos municípios localizados na faixa de fronteira dificilmente são atendidas em nível federal, devido às dificuldades de reivindicação das prefeituras e sociedade civil frente aos ministérios. Ademais, para Peixoto, haveria ainda uma grande escassez de iniciativas de cooperação internacional na região de fronteira com a Bolívia. As diferenças legislativas foram apontadas pelo coordenador como o principal empecilho para o desenvolvimento sustentável das cidades-gêmeas entre os dois países (GIMENEZ, 2015).

As divergências legislativas representam um fator importante no desenvolvimento da cooperação (COCKAYNE, 2007), principalmente quando envolvem a atuação conjunta de agências estrangeiras. No caso do Brasil com a Bolívia, a principal divergência refere-se à questão do cultivo da folha de coca, o qual é permitido e controlado pelo país andino, enquanto é totalmente proibido no território brasileiro. Assim, para evitar conflitos políticos e diplomáticos, as operações voltam-se, principalmente, para outros aspectos da luta contra o tráfico de drogas.

Santana, então diretor de investigação da PF, afirmou que os policiais brasileiros sempre atuaram em território boliviano, para além da região de fronteira. Mesmo impedidos de operarem armas, os agentes trocam informações e coordenam operações conjuntas de caráter ostensivo com as forças de segurança da Bolívia. Ademais, sempre houve o intercâmbio de agentes da PF com a FELCN, para conhecer e auxiliar nas bases de inteligência de cada país (GIMENEZ, 2015). Ao longo dos anos de 2008 a 2012, foram realizadas algumas operações conjuntas nesse sentido entre os dois países, envolvendo instituições policiais e militares.

De 27 de março à 4 de abril de 2011 foi deflagrada a Operação BRABO entre a PF e a FELCN, fruto do acordo assinado entre os dois países no final de março, durante a VII Comissão Mista sobre Drogas e Temas Conexos. Em nove dias de operação, os agentes realizaram tarefas de fiscalização e apreensão nas estradas que ligam as cidades fronteiriças de Corumbá, Puerto Quijarro e Puerto Suárez (ROSSITER, 2011; VITORINO, 2011). Em outro momento, no final de janeiro de 2012, foi a polícia brasileira que deu apoio, através do fornecimento de informações, para a FELCN numa operação conjunta que resultou na captura de 12 pessoas envolvidas com o crime organizado na região de fronteira de San Matías, na Bolívia, e Cáceres, no Brasil. As informações da polícia brasileira revelaram as fichas criminais dos envolvidos no tráfico de cocaína entre os países (PORTALES, 2012).

16 A CDIF foi criada em 2010, pelo Ministério da Integração, para articular as demandas e necessidades dos municípios de região de fronteira com as políticas governamentais de desenvolvimento e sustentabilidade. 
Operações conjuntas também foram realizadas entre as Forças Armadas do Brasil e da Bolívia. Entre os dias 23 e 27 de agosto de 2010, foi realizado o Exercício Operacional BOLBRA I, entre a Força Aérea Brasileira (FAB) e a Força Aérea Boliviana (FBol). Os militares brasileiros foram enviados à Bolívia para treinar missões de interceptação e ataque ao solo. O objetivo era fortalecer a relação entre as forças aéreas de ambos os países (OPERAÇÃO BOLBRA I, 2010). Desde 2010 também são realizados exercícios conjuntos da Marinha do Brasil e da Armada Boliviana, denominados de BRASBOL (DIAS, 2015).

Em 22 de novembro de 2011 foi deflagrada a Operação Ágata 3, na região de fronteira Norte e Centro-Oeste do Brasil. Durante os 15 dias de ações, a Ágata 3 mobilizou quase sete mil homens das Forças Armadas (MARINHA..., [2011]), além de equipes da Força Nacional de Segurança Pública (FNSP), Agência Brasileira de Inteligência (Abin), das polícias civis e militares do Mato Grosso, Acre e Rondônia, da Receita Federal e do Departamento da Polícia Federal. Por envolver localidades na faixa de fronteira com a Bolívia, três oficiais do Exército, Marinha e Aeronáutica bolivianos participaram como observadores da operação nas proximidades de Guajará Mirim (cidade localizada em Rondônia, que é cidadegêmea de Guayaramerín, no departamento de Beni, na Bolívia) (OPERAÇÃO MILITAR..., 2011).

De acordo com o balanço da operação, a Ágata 3 conseguiu apreender dezenas de veículos utilizados no contrabando de droga, quase R $\$ 500$ mil em dinheiro, além de 17,8 kg de pasta base de cocaína, mais de $600 \mathrm{~kg}$ de maconha e 34 armas (OPERAÇÃO MILITAR..., 2011). O vice-presidente na época, Michel Temer, e o ministro da Defesa, Celso Amorim, elogiaram a atuação das Forças Armadas e consideraram que houve uma evolução na capacidade do país de combater o crime organizado nas regiões de fronteira (ÁGATA 3..., 2011). Ademais, Temer destacou a importância dessas operações dissuasórias das Forças Armadas, que contribuiriam para o trabalho posterior da Polícia Federal, no âmbito da Operação Sentinela ${ }^{17}$ (OPERAÇÃO MILITAR..., 2011).

A operações analisadas, desenvolvidas na faixa de fronteira de Brasil e Bolívia durante os anos de 2008 a 2012, foram dispostas no quadro a seguir:

17 A Operação Sentinela, assim como a Ágata, é um eixo de ação do Plano Estratégico de Fronteiras (Pefron). Nesse caso, a responsabilidade das ações, realizadas pela Polícia Federal, fica a cargo do Ministério da Justiça. 


\section{Quadro 2 - Operações realizadas pelas forças de segurança brasileiras e bolivianas na região de fronteira, 2008-2012}

\begin{tabular}{|c|c|c|c|}
\hline DATA & DENOMINAÇÃO & CONTINGENTE & LOCAL \\
\hline $11 / 2009$ & Operação Cadeado & $\begin{array}{l}\text { CMO; DPF; Ibama; } \\
\text { Receita Federal. }\end{array}$ & $\begin{array}{l}\text { Região de fronteira do } \\
\text { Brasil com a Bolívia e o } \\
\text { Paraguai. }\end{array}$ \\
\hline $11 / 2010$ & Operação Cadeado IV & $\begin{array}{l}\text { CMO; Forças Armadas; } \\
\text { Secretaria de Estado } \\
\text { de Justiça e Segurança } \\
\text { Pública. }\end{array}$ & $\begin{array}{l}\text { Região de fronteira do } \\
\text { Brasil com a Bolívia. }\end{array}$ \\
\hline 09-10/2010 & Operação Curare III & $\begin{array}{l}17^{a} \text { Brigada de Infantaria } \\
\text { de Selva. }\end{array}$ & $\begin{array}{l}\text { Região de fronteira } \\
\text { nos estados do Acre e } \\
\text { Rondônia. }\end{array}$ \\
\hline $\begin{array}{l}27 / 03 / 2011- \\
04 / 03 / 2011\end{array}$ & Operação BRABO & $\begin{array}{l}\text { PF brasileira e Polícia } \\
\text { boliviana. }\end{array}$ & $\begin{array}{l}\text { Cidades de Corumbá, } \\
\text { Puerto Quijarro e } \\
\text { Puerto Suárez. }\end{array}$ \\
\hline $08 / 2010$ & BRASBOL & $\begin{array}{l}\text { Marinha brasileira e } \\
\text { boliviana. }\end{array}$ & ------- \\
\hline $23-27 / 08 / 2010$ & BOLBRA I & FAB e FABol. & Bolívia. \\
\hline $\begin{array}{l}22 / 11 / 2011- \\
07 / 12 / 2011\end{array}$ & Operação Ágata 3 & $\begin{array}{l}\text { Forças Armadas; FNSP; } \\
\text { ABIN; Polícias militares e } \\
\text { civis; Forças Armadas da } \\
\text { Bolívia. }\end{array}$ & $\begin{array}{l}\text { Fronteira Norte e } \\
\text { Centro-Oeste do Brasil. }\end{array}$ \\
\hline $01 / 2012$ & ------- & $\begin{array}{l}\text { FELCN com apoio da } \\
\text { Polícia Federal brasileira. }\end{array}$ & $\begin{array}{l}\text { Região de fronteira de } \\
\text { San Matías, na Bolívia, } \\
\text { e Cáceres, no Brasil. }\end{array}$ \\
\hline
\end{tabular}

Fonte: elaborado pela autora com base em reportagens e notícias de periódicos (2017).

As operações expressam, portanto, o lado prático dos acordos e parcerias estabelecidos entre agentes e ministérios do Brasil e da Bolívia, no que concerne ao problema do tráfico de substâncias entorpecentes, principalmente a cocaína. Diante da saída da DEA, a Polícia Federal brasileira e as Forças Armadas constituíramse como importantes parceiros operacionais das forças de segurança bolivianas. Não obstante, essa cooperação entre as agências policiais e militares de ambos os países não significou um confrontamento com a grande potência regional. Conforme assinalado anteriormente, o envolvimento do Brasil na cooperação com a Bolívia respondeu aos anseios estadunidenses de garantir a manutenção da luta contra o tráfico de drogas na região. 
Ademais, além dos acordos entre a Bolívia e o Brasil significarem a manutenção dos interesses dos Estados Unidos, no que concerne a "guerra às drogas", a diplomacia e governo brasileiros exerceram um importante papel na reaproximação e restabelecimento da cooperação formal do país andino com o governo estadunidense. Em um telegrama emitido pela embaixada dos Estados Unidos em Brasília, em setembro de 2009, há descrição e comentários sobre conversas entre as autoridades brasileiras e bolivianas a respeito do estabelecimento de um acordo entre os três países (WIKILEAKS, 2009 b). O governo brasileiro ocupou um papel de facilitador e intermediador do processo de cooperação, assinalando ao governo estadunidense quais seriam os melhores momentos para uma aproximação e quais seriam os pontos delicados da negociação. A Bolívia, por exemplo, não estaria disposta em retomar uma cooperação nos antigos termos. Os Estados Unidos teriam, portanto, que respeitar a soberania boliviana (WIKILEAKS, 2009 b).

Após três anos de negociação, o acordo tripartite Bolívia-Brasil-Estados Unidos foi assinado em janeiro de 2012 e deu origem ao "Projeto Piloto de Sistema de Controle da Redução de Cultivos Excedentário de Coca”. De acordo com esse projeto trilateral, baseado no princípio da responsabilidade compartilhada, os Estados Unidos seriam responsáveis pelo treinamento e o fornecimento de equipamentos (como o Sistema de Posicionamento Global e um sistema de medição a laser) para a análise de imagens e dados que seriam colhidos pelo Brasil, enquanto a Bolívia se concentraria no trabalho de campo (BRASIL..., 2012; QUIROGA, 2012). O projeto ainda existe no papel, mas sem conseguir avançar nos objetivos estabelecidos. As sucessivas desavenças entre o governo boliviano e o estadunidense e os relatórios anuais emitidos pelo Estados Unidos (International Narcotics Control Strategy Report), que afirmam que a Bolívia tem fracassado nos seus esforços e obrigações nos acordos internacionais contra as drogas, dificultam o aprofundamento da cooperação.

\section{Considerações finais}

Este artigo analisou a cooperação entre a Bolívia e o Brasil no combate ao tráfico de drogas. Conforme apresentado, as agências e ministérios brasileiros configuraram-se como importantes parceiros da Bolívia, principalmente após a expulsão da agência estadunidense, DEA, em novembro de 2008. Inclusive, de acordo com os relatos de documentos apresentados ao longo do artigo, a 
aproximação entre os dois países seguiu o interesse dos Estados Unidos de que fosse mantido o controle e o combate aos grupos narcotraficantes na região. Assim, diversos acordos foram celebrados e resultaram na realização de algumas operações e atividades conjuntas, com destaque para a troca de informações, tecnologias e experiências - diante da impossibilidade de agir para além da fronteira nacional, o principal instrumento de cooperação entre os dois países foi a realização de seminários e exercícios binacionais. O estreitamento da relação entre o Brasil e a Bolívia também contribuiu para que o governo brasileiro atuasse como intermediador nas negociações do país andino com a grande potência regional. Como resultado, em janeiro de 2012, foi assinado o acordo tripartite Bolívia-Brasil-Estados Unidos.

Ademais, a análise dos acordos e operações de policiamento realizados na fronteira entre o Brasil e a Bolívia destaca a grande importância e autonomia dos representantes dos ministérios da Justiça de ambos os países na cooperação bilateral, além da atuação dos adidos militares e policiais brasileiros na embaixada em La Paz. Muitos dos convites destinados às autoridades bolivianas, para os seminários e reuniões realizados no Brasil, referentes ao combate à criminalidade, e para participarem como observadores nas operações desenvolvidas pelas forças de segurança brasileira na região de fronteira, foram emitidos através desses representantes das Forças Armadas e das agências policiais localizados na Bolívia. Apesar da existência de tratados estabelecidos pelo Ministério das Relações Exteriores, compreendemos que o caráter dos acordos e das operações realizados entre os dois países reflete o grau de autonomia que as burocracias estatais podem exercer, contribuindo para a condução e execução da cooperação internacional, às vezes de forma mais expressiva que os atores tradicionalmente ligados à execução da política externa.

\section{Referências}

ÁGATA 3 - "Nós vamos continuar com essas operações", diz Vice-Presidente. DefesaNet, 7 dez. 2011. Disponível em: < http://www.defesanet.com.br/defesa/noticia/3877/agata3----nos-vamos-continuar-com-essas-operacoes \% E2 \% 80\% 9D--diz-vice-presidente > . Acesso em: 8 out. 2016.

ASSOCIAÇÃO NACIONAL DOS DELEGADOS DE POLÍCIA FEDERAL -ADPF. Limites para o Crime. Revista Prisma. Ano XXII, nº 67. Abr./maio/jun. 2011. P. 26-29. 
BIATO, M. F.. Brasil en la cooperación regional para la lucha contra la violencia y el crimen organizado. Revista CIDOB, Barcelona v. 97/98, 2012, p. 117-133. Disponível em: < http://www.cidob.org/noustack/articulos/revista_cidob_d_afers_ internacionals/97_98/brasil_en_la_cooperacion_regional_para_la_lucha_contra_la_ violencia_y_el_crimen_organizado > . Acesso em: 8 maio 2015.

BOLIVIA. Proyecto de Ley $\mathrm{n}^{\circ}$ 007/2017-2018. Ley General de la Coca. La Paz: Asamblea Legislativa Plurinacional de Bolivia. Cámara de Diputados, 2017, 12p. Disponível em: < http://ain-bolivia.org/wp-content/uploads/Nueva-Ley-Coca-Original.pdf > . Acesso: em 27 nov. 2018.

BRASIL. Constituição (1988). Constituição da República Federativa do Brasil. Brasília, DF: Câmara dos Deputados: Centro de Documentação e Informação, 2016, 124p. Disponível em: < http://www2.camara.leg.br/atividade-legislativa/legislacao/ Constituicoes_Brasileiras/constituicao1988.html/ConstituicaoTextoAtualizado_EC92. pdf > . Acesso em: 5 jul. 2016.

BRASIL. Decreto No 7.496, de 8 de junho de 2011. Institui o Plano Estratégico de Fronteiras. Diário Oficial da União, Brasília, DF, 8 jun. 2011. Disponível em: < http://www. planalto.gov.br/ccivil_03/_Ato2011-2014/2011/Decreto/D7496.htm > . Acesso em: 5 jul. 2016.

BRASIL. Lei Complementar No 117, de 2 de setembro de 2004. Altera a Lei Complementar no 97 , de 9 de junho de 1999, que dispõe sobre as normas gerais para a organização, o preparo e o emprego das Forças Armadas, para estabelecer novas atribuições subsidiárias. Diário Oficial da União, Brasília, DF, 2 de set. 2004b. Disponível em: < http://www.planalto.gov.br/CCivil_03/LEIS/LCP/Lcp117.htm > . Acesso em: 5 jul. 2016.

BRASIL. Ministério Das Relações Exteriores. Acordo de Cooperação para Impedir o Uso Ilegal de Precursores e Substâncias Químicas essenciais para o Processamento de Entorpecentes e Substâncias Psicotrópicas. La Paz, 26 de jul. de 1999. Disponível em: < http://dai-mre.serpro.gov.br/atos-internacionais/bilaterais/1999/b_39> . Acesso em: 5 abr. 2016.

BRASIL. Ministério Das Relações Exteriores. Convênio de Assistência Recíproca para a Repressão do Tráfico Ilícito de Drogas que produzem Dependência. Brasília, 17 de ago. de 1977. Disponível em: < http://dai-mre.serpro.gov.br/atos-internacionais/ bilaterais/1977/b_60 >. Acesso em: 5 abr. 2016.

BRASIL. Ministério Das Relações Exteriores. Protocolo Adicional ao Convênio de Assistência Recíproca para a Repressão do Tráfico Ilícito de Drogas que produzem Dependência. La Paz, 2 de ago. de 1988. Disponível em: < http://dai-mre.serpro. gov.br/atos-internacionais/bilaterais/1988/b_59>. Acesso em: 5 abr. 2016. 
BRASIL, EE.UU e Bolivia firman acuerdo para reducir coca ilegal. La Patria, 21 enero 2012. Disponível em: < http://lapatriaenlinea.com/?nota $=95438>$. Acesso em: 15 jan. 2017.

BRIENEN, Marten W. Bolivian Drug Policy under the Morales Administration. In: BAGLEY, Bruce M.; ROSEN, Jonathan D. Rosen (Eds.) Drug Trafficking, Organized Crime, and Violence in the Americas Today. University Press of Florida, 2015. P. 203-222.

CASON, Jeffrey W; POWER, Timothy J. "Presidentialization, Pluralization and the Rollback of Itamaraty: Explaining Change in Brazilian Foreign Policy Making in the Cardoso-Lula Era”. International Political Science Review, vol.30, n.2, 2009.

COCKAYNE, James. Transnational Organized Crime: Multilateral Responses to a Rising Threat. Coping with Crisis - Working Paper Series, Abril 2007.

CONROY, Bill; FRIEDMAN-RUDOVSKY, Jean; VIANA, Natália. WIKILEAKS: Agentes da DEA expulsos da Bolívia por espionagem vieram para o Brasil. Agência Pública, 5 jul. 2011. Disponível em: < http://apublica.org/2011/07/agentes-da-dea-expulsosda-bolivia-por-espionagem-vieram-para-o-brasil/ > . Acesso em: 04 ago. 2017.

CRUZ, Elaine P. Brasil e Bolívia assinam acordo para combater o tráfico de drogas e armas. Agência Brasil, 16 dez. 2010. Disponível em: < http://memoria.ebc.com.br/ agenciabrasil/noticia/2010-12-16/brasil-e-bolivia-assinam-acordo-para-combatertrafico-de-drogas-e-armas > . Acesso em: 18 nov. 2016.

CUIABANO, Lidiana. Seajusp é parceirado Exército em mais uma edição da Operação Cadeado. Jornal Oeste, 9 nov. 2010. Disponível em: < http://www.jornaloeste.com. br/noticias/exibir.asp?id = 13121\&noticia = sejusp_e_parceira_do_exercito_em_mais_ uma_edicao_da_operacao_cadeado_>. Acesso em: 8 out. 2016.

DELGADO, Ana Carolina; CUNHA FILHO, M. C. Ideologia e pragmatismo: a política externa de Evo Morales. World Tensions/Tensões Mundiais, v. 6, n. 10, 2010.

DEL PRADO, José Carlos C. N.. Estudio Exploratorio sobre Problematicas de Seguridad em Ciudades de Frontera. Caso: Ciudade de Cobija. Fundación Friedrich Ebert Bolívia. Nov. 2012.

DIAS, Michelle G.. Cooperações Bilaterais do Brasil com Bolívia, Colômbia e Peru no Combate ao Tráfico de Drogas Ilícitas. In: I Seminário Internacional de Ciência Política. Universidade Federal do Rio Grande do Sul, Porto Alegre, set. 2015.

DIAS JUNIOR, Mérces; CRIVELATTI, Quelim D.; DA COSTA, Edgar A.. Gestão da Segurança Pública na Fronteira Brasil-Bolívia em Corumbá-MS. Segurança Pública \& Cidadania, v. 5, n. 2, 2013, p. 33-59. Disponível em: < https://periodicos.dpf.gov.br/index.php/ RSPC/article/view/1 > . Acesso em: 23 abr. 2016.

DREYFUS, Pablo. Mapeo del Crimen Organizado de Brasil. In: MATHIEU, H. M; ARREDONDO, P. R. (Eds.) Anuario 2009 de Seguridad em America Latina y el Caribe. Bogotá, jun. 2009. 
GIMENEZ, Heloísa M. Defesa Nacional, Segurança Pública e Relações Internacionais: uma análise sobre a fronteira Bolívia-Brasil (2005-2014). 2015. 493 f. Tese (Doutorado em Relações Internacionais) Instituto de Relações Internacionais, Universidade de Brasília, Brasília, 2015.

GISBERT, Carlos D. M.. Bolivia y Brasil: Los Meandros Del Camino. In: Plataforma Democrática. Working Paper n³, jul. 2011, p.2-21.

GRISAFFI, Thomas; LEDEBUR, Kathryn. Citizenship or Repression? Coca, Eradication and Development in the Andes. Stability: International Journal of Security and Development, v. 5, n. 1, 2016.

HIRST, Mônica.. A Presença do Brasil na Bolívia: Diálogo Político, Vínculos Econômicos e Cooperação Horizontal. (Texto para Discussão) Instituto de Pesquisa Econômica Aplicada. Brasília, setembro 2013.

LEICHTMAN, Ellen C. Bolivia, coca, and US foreign policy. Critical Criminology, v. 9, n. 1-2, p. 63-84, 2000.

LISBOA, Marcelino T. A Política Externa da Bolívia e a questão da coca (2006-2014). Estudos internacionais: revista de relações internacionais da PUC Minas, v. 3, n. 2, p. 267-286, 2015.

MACHADO, Lia O. Medidas institucionais para o controle do tráfico de drogas e da lavagem de dinheiro e seus efeitos geoestratégicos na região Amazônica brasileira. Cadernos IPPUR/UFRJ/Instituto de Pesquisa e Planejamento Urbano e Regional da Universidade Federal do Rio de Janeiro. Ano XXI. Nº1. Jan../jul. 2007, p. 9-31.

MACHADO, Lia O. A Estratégia Nacional de Defesa, A Geografia do Tráfico de Drogas Ilícitas e a Bacia Amazônica Sul-Americana. In: Seminário de Defesa e Desenvolvimento Sustentável da Amazônia/ECEME. Rio de Janeiro, ago. 2010, p. 99-107.

MARINHA do Brasil participa da Operação Ágata 3. A Crítica [2011]. Disponível em: $<$ http://www.acritica.net/editorias/geral/marinha-do-brasil-participa-da-operacaoagata-3/52181/ > . Acesso em: 8 out. 2016.

MARREIRO, Flávia. Amorim 'relança' cooperação com Bolívia. Folha de S. Paulo, 31 out. 2011. Disponível em: < http://www1.folha.uol.com.br/fsp/mundo/ft3110201108. htm > . Acesso em: 18 nov. 2016.

MAYORGA, Fernando. Bolivia: Seguridad regional, crisis política y conflitos. In: MATHIEU, H. M; ARREDONDO, P. R. (Orgs). Anuario 2009 de Seguridad em America Latina y el Caribe. Bogotá, junio de 2009.

NACIONES UNIDAS: Junta Internacional de Fiscalización de Estupefacientes. Informe de la Junta Internacional de Fiscalización de Estupefacientes correspondiente a 2017. Naciones Unidas, Viena, 2018. Disponível em: < http://www.incb.org/documents/ Publications/AnnualReports/AR2017/Annual_Report/S_2017_AR_ebook.pdf > . Acesso em: 27 nov. 2018. 
OPERAÇÃO BOLBRA I. Poder Aéreo, 25 ago. 2010. Disponível em: < http://www.aereo. jor.br/2010/08/25/operacao-bolbra-i/ > . Acesso em: 25 nov. 2015.

OPERAÇÃO Cadeado “fecha” fronteira de Corumbá com a Bolívia. Jornal Diário Corumbaense, 10 nov. 2009. Disponível em: < https://diarionline.com.br/?s $=$ noticia\&id $=7198>$. Acesso em: 12 jun. 2016.

OPERAÇÃO Curare III. Forças Terrestres, 29 set. 2011. Disponível em: < http://www. forte.jor.br/2011/09/29/operacao-curare-iii-17 \% C2 \% AA-brigada-de-infantaria-deselva-avex-e-orgaos-governamentais-contra-delitos-transfronteiricos/ > . Acesso em: 12 jun. 2016.

OPERAÇÃO militar reduz oferta de drogas na faixa de fronteiras. Portal Brasil, 8 dez. 2011. Disponível em: < http://www.brasil.gov.br/saude/2011/12/operacao-militarreduz-oferta-de-drogas-na-faixa-de-fronteiras > . Acesso em: 8 out. 2016.

PF vai assumir combate ao tráfico na Bolívia. Notícias Terra, 28 dez. 2008. Disponível em: < http://noticias.terra.com.br/brasil/noticias/0,,OI3415853-EI5030,00-PF + vai + ass umir + combate + ao + trafico + na + Bolivia.html\#tarticle > . Acesso em: 15 abr. 2016 POLÍCIAS do Brasil e da Bolívia assinam acordo de cooperação no combate ao crime organizado. Agência Brasil, 18 fev. 2009. Disponível em: < http://memoria.ebc. com.br/agenciabrasil/noticia/2009-02-18/policias-do-brasil-e-da-bolivia-assinamacordo-de-cooperacao-no-combate-ao-crime-organizado > . Acesso em: 15 abr. 2016. PORTALES. Brasil e Bolívia juntos contra o narcotráfico e o crime organizado. Diálogo. Revista Militar Digital, 19 mar. 2012. Disponível em: < https://dialogo-americas. $\mathrm{com} / \mathrm{pt} /$ articles/brasil-e-bolivia-juntos-contra-narcotrafico-e-crime-organizado $>$. Acesso em: 8 out. 2016.

PROCÓPIO FILHO, Argemiro; VAZ, Alcides Costa. O Brasil no contexto do narcotráfico internacional. Revista Brasileira de Política Internacional, v. 40, n. 1, p. 75-122, 1997. Disponível em: http://www.scielo.br/scielo.php?pid = S0034$73291997000100004 \&$ script $=$ sci_arttext > . Acesso em: 13 out. 2015.

QUIROGA, Carlos. Bolívia, Brasil e EUA estabelecem parceria contra drogas. Reuters Brasil, 20 jan. 2012. Disponível em: < http://br.reuters.com/article/topNews/ idBRSPE80K00220120121 > . Acesso em: 15 jan. 2017.

RODRIGUES, Thiago. Narcotráfico: uma guerra na guerra. 2.ed. São Paulo: Desatino, 2012, 144p.

RODRIGUES, Thiago. Política e drogas nas Américas. São Paulo: EDUC:FAPESP, 2004, 334p.; 23cm. (Hipótese).

ROSSITER, Sheena. Brasil e Bolívia assinam acordo de combate ao narcotráfico. Diálogo. Revista Militar Digital, 10 jun. 2011. Disponível em: < https://dialogo-americas.com/ pt/articles/brasil-e-bolivia-assinam-acordo-de-combate-ao-narcotrafico > . Acesso em: 8 out. 2016. 
SCHULTZE-KRAFT, Markus. Actualización y ampliación de los mapeos sobre el crimen organizado en Colombia y la región andina, 2008-2009. In: MATHIEU, H; GUARNIZO. C. N (Eds.). Anuario 2010 de la Seguridad Regional en América Latina y el Caribe. Bogotá, oct. 2010.

SOUSA, Rosinaldo Silva. Organização Política e Cultivos Ilícitos de Coca na Bolívia. Uma Abordagem Etnográfica. RBCS. Vol. 25. Nº 73. Junho/2010. P.27-40.

UNITED NATIONS. World Drug Report 2012. United Nations Office on Drugs and Crime. Vienna, June 2012. 102p.

UNITED NATIONS. World Drug Report 2018. United Nations Office on Drugs and Crime. United Nations, June 2018.

UNITED NATIONS OFFICE ON DRUGS AND CRIME. Bolívia, Brasil e UNODC fortalecem cooperação para combater o tráfico de drogas e o crime organizado. UNODC, 6 abr. 2011. Disponível em: < https://www.unodc.org/lpo-brazil/pt/frontpage/2011/04/06bolivia-brasil-e-unodc-fortalecem-cooperacao-para-combater-o-trafico-de-drogas-eo-crime-organizado.html > . Acesso em: 18 nov. 2016.

UNITED NATIONS OFFICE ON DRUGS AND CRIME. Brasil e Bolívia discutem cooperação bilateral em matéria criminal. UNODC, 27 out. 2010. Disponível em: < https://www. unodc.org/lpo-brazil/pt/frontpage/2010/10/27-brasil-e-bolivia-discutem-cooperacaobilateral-em-materia-criminal.html > . Acesso em: 18 nov. 2016.

VITORINO, Paula. Operação BRABO fiscaliza fronteira de MS com a Bolívia para coibir crimes. Campo Grande News, 29 mar. 2011. Disponível em: < http://www. campograndenews.com.br/cidades/interior/operacao-brabo-fiscaliza-fronteira-dems-com-a-bolivia-para-coibir-crimes > . Acesso em: 7 jun. 2016.

WIKILEAKS. End-Use Monitoring Report: Brazil, 2009. Wikileaks, 5 feb. 2010. Disponível em: < https://wikileaks.org/plusd/cables/10BRASILIA114_a.html > Acesso em: 30 jul. 2017.

WIKILEAKS. Keeping lit Brazil and Bolivia's flickering interest in trilateral counternarcortics cooperation with U.S. Wikileaks, 14 set. 2009b. Disponível em: < https://wikileaks. org/plusd/cables/09BRASILIA1140_a.html > . Acesso em: 30 jul. 2017.

WIKILEAKS Cablegate. Brazil's Foreign Ministry Understands DEA Role in Regional Counterdrug Fight. Wikileaks, 4 dec. 2008. Disponível em: < http://wikileaks. vicepresidencia.gob.bo/BRAZIL-S-FOREIGN-MINISTRY > . Acesso em: 27 jul. 2017.

WIKILEAKS Cablegate. Engaging Brazil on Regional Counter-Narcotics Cooperation. Wikileaks, 12 mar. 2009a. Disponível em: < http://wikileaks.vicepresidencia.gob. bo/ENGAGING-BRAZIL-ON-REGIONAL > . Acesso em: 30 jul, 2017. 